\title{
Psychological Climate's Effect on Stress among Public Servants
}

This forthcoming peer-reviewed paper has been accepted at the virtual 81st Annual Meeting of the Academy of Management taking place on 29 July - 4 August 2021. The complete paper abstract will be published in the AOM Annual Meeting Proceedings.

\section{Vadym Mozgovoy ${ }^{\text {a* }}$}

${ }^{\text {a}}$ Faculty of Law, Criminal Justice and Public Administration, University of Lausanne, Lausanne, Switzerland *Corresponding author: Swiss Graduate School of Public Administration, University of Lausanne, Rue de la Mouline 28, Chavannes-près-Renens 1022, Switzerland; ORCID: orcid.org/0000-00015322-3740; Email address: vadym.mozgovoy@unil.ch; mozgovoy.vadym@gmail.com

\begin{abstract}
In public administration, organizational well-being is a concern. This research hypothesized and found that the psychological climate decreases felt stress without a simultaneous reciprocal impact, based on a cross-sectional survey of 350 Swiss public servants. The researchers used structural equation modeling and supplementary mediation models. The findings indicate that the psychological environment for public servants is characterized by three out of six dimensions role clarity, contribution, and supportive management. Higher role clarity reduces stress role clarity moderately and significantly reduces stress, while supportive management only does so to a limited degree. This impact was most noticeable among public employees who wanted to stay on their current career path.
\end{abstract}

\section{Keywords:}

Psychological climate; public management; stress 